\title{
Endovascular Management of Head and Neck Vascular Malformations
}

\author{
Matthew P. Lungren · Manish N. Patel
}

Published online: 21 June 2014

(C) Springer Science+Business Media New York 2014

\begin{abstract}
Vascular malformations are congenital lesions caused by errors in endothelial development. Mulliken's classification of vascular malformations subdivides lesions into high-flow (such as arteriovenous malformations) and low-flow lesions (such as venous and lymphatic malformations). Although they can occur virtually anywhere in the body, the majority occur in the head and neck. The therapeutic management of vascular malformations is challenging even for highly experienced practitioners; they are often complex lesions that require a specialized multidisciplinary team approach for optimal treatment. Currently, endovascular therapeutic techniques, such as sclerotherapy, with or without adjunctive surgical resection, are among the first-line treatment options for vascular malformations. There are a wide variety of embolosclerotherapy agents which have been used effectively to treat vascular malformations. This article presents a brief overview of the endovascular management of craniofacial vascular malformations.
\end{abstract}

Keywords Vascular malformations · Endovascular management $\cdot$ Sclerotherapy

\footnotetext{
M. P. Lungren

Department of Pediatric Radiology, Lucile Packard Children's Hospital, Stanford University School of Medicine, Stanford, CA 94305-5913, USA

e-mail: mlungren@gmail.com

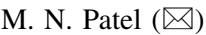

Department of Radiology, Cincinnati Children's Hospital Medical Center, University of Cincinnati College of Medicine, 3333 Burnet Ave. MLC 5031, Cincinnati, OH 45229, USA e-mail: manish.patel@cchmc.org
}

\section{Introduction}

Vascular malformations are uncommon lesions in the head and neck, estimated to occur in about $0.3 \%$ of live births, with as many as $90 \%$ clinically recognized within the first month of life [1,2]. They grow commensurate with the size of the child, often demonstrating growth acceleration during puberty or pregnancy. Based on pathologic and molecular genetic classification, vascular malformations are categorized into two main groups: high-flow and lowflow lesions [2, 3]. High-flow lesions comprise arterial malformations, arteriovenous malformations (AVMs), capillary AVMs, and arteriovenous fistulae. Low-flow vascular malformations are characterized by the dominant endothelial cell component: capillary, venous, lymphatic or, combined (e.g., capillary-lymphatic venous malformation, lymphovenous malformation).

The management of vascular malformation patients, some of whom are quite complex, have been repeatedly shown to benefit from a multidisciplinary approach [4-6]. Practitioners from vascular surgery, orthopedic surgery, plastic/reconstructive surgery, otolaryngology, ophthalmology, diagnostic and interventional radiology, physical and rehabilitation medicine, hematology-oncology, psychiatry, and patient advocacy all potentially play important roles in the management of these complex patients. Head and neck vascular malformation treatment, in particular, often is prolonged and in most lesions staged in a stepwise fashion by multiple practitioners.

The approaches for treating head and neck vascular malformations are quite variable and include observation, medical management, surgical resection, endovascular sclerotherapy, or ablation, and often, a combination of several approaches. Many factors play into the management decision, most predominantly the lesion type, size, 
and anatomic location. For example, lesions that extend into the oral cavity or airway may require airway management intervention as part of a staged treatment approach. Most lesions involving the tongue and buccal mucosa are generally treated with surgical resection, although combined therapy with endovascular, laser, or radiofrequency ablation has been reported [7, 8]. The purpose of this review is to provide the reader a detailed overview of endovascular management techniques for craniofacial vascular malformations.

\section{Venous Malformations}

Venous malformations (VM) are rare congenital lesions with an estimated incidence of $0.01 \% ; 40 \%$ of these are found in the head and neck, $40 \%$ in the trunk, and $20 \%$ in the extremities [3]. VMs often reside within a broad phenotypic spectrum which most often includes lymphatic malformation elements, as illustrated by venolymphatic malformations (Fig. 1). Factors that can lead to altered morphology include hormonal changes, trauma, and prior surgery and/or endovascular intervention. Clinically, typical VMs are bluish to purplish superficial lesion(s) which are compressible and characteristically expand with the Valsalva maneuver or when manipulated into a dependent position. VMs do not have arterial supply, and as a result, on physical exam will not demonstrate a thrill or increase in skin temperature. The architecture of most focal lesions is most typically composed of low pressure inflow into a dilated abnormal channel(s), with concomitant low pressure drainage; these flow characteristics predispose to intralesional thrombosis.

VM patients present with pain, which is attributed to focal thrombosis, local inflammatory fibrosis, and associated deformities in underlying bone, muscle, or joints. In head and neck VM, deep structure involvement can lead to bleeding via muscosal surfaces; swelling too can be problematic in circumstances in which adjacent structures such as the orbit, airway, or nerves are impacted [9, 10, 11•]. Bleeding and airway compromise is common with extensive head and neck mucosal lesions, and the goal of therapy is to decrease the chances of bleeding and relieve any airway compromise. For most patients with VM, recurrence is more the rule than the exception, attributed to both lumen recanalization and hypertrophy of small portions of the lesion that remain untreated. In addition, VM lesions will tend to quickly grow during characteristic provocative events, such as direct trauma, and systemic hormonal changes such as puberty, pregnancy, birth control pills, etc [11•]. Due to the typically chronic course of most VM, objectives of treatment center on controlling pain and reducing the appearance of the lesion or visible deformities; cosmesis is of particular concern to head and neck VM patients, and the visibility of the lesion has been shown to severely impact quality of life [12].

Sclerotherapy, injecting chemicals into the malformation with the intention of thrombosing and obliterating the lumen, is often the first-line approach in management of VM (Table 1) [13-15]. In most cases, sclerotherapy is performed via direct puncture of the lesion under direct image guidance (ultrasound or fluoroscopy). In our practices, a small (20-22G) angiocath-sheathed needle is advanced percutaneously under ultrasound visualization. Contrast material is then injected into the lesion to define the anatomic boundaries, communication with adjacent vascular structures, proximity to nerves, determine the flow rate, and to estimate the approximate volume of the lesion (Fig. 2). Flow rate and draining veins, if present, play critical roles in choice and quantity of sclerotherapy agent used for treatment. For example, when a draining vein is visualized, determination must be made as to whether a direct conduit into the central veins exists, in which case the risk of non-target embolization rises [16-18]. Large or central draining veins can be compressed manually during sclerosant injection or via endovascular balloon catheter deployment. In certain cases, draining veins can be embolized directly, with coils or NBCA before the injection of the sclerotherapy agent [17, 19]. These strategies will reduce non-target embolization and help ensure that the highest possible concentration of the sclerotherapy agent will remain in the VM.

Sclerosant is injected using fluoroscopic or ultrasound visualization to evaluate in real time for the presence of extravasation into the extravascular tissues, and to monitor for potential egress of the agent out from the lesion; both can be caused by overfilling/overinjection. Some authors advocate a 2-needle access technique to avoid overfilling whereby a second percutaneous access is obtained into the VM and is allowed to decompress the lesion during sclerosant injection $[14,20]$. During injection, it is critically important to evaluate the overlying skin for ischemic change; pallor, blanching, or increased tightness of the overlying tissues should signal cessation of treatment. In our practices, cold saline compresses are used immediately following sclerosant injection in an effort to vasoconstrict regional tissue and prevent sclerosant leaking into surrounding tissues.

Special precautions should be taken during sclerotherapy of head and neck VMs. For example, when performing sclerotherapy in the upper $1 / 3$ of the face, the possibility of accidental embolization of the cavernous sinus should always be considered. Further, facial venous connections may connect to the angular vein, which drains superiorly to join the superior ophthalmic vein and cavernous sinus. Often manual compression of the angular vein against the maxilla 
Fig. 1 Low-flow

(venolymphatic) malformation during serial sclerotherapy treatment. (a) Contrastenhanced axial CT of the neck demonstrates a low attenuation right submandibular cystic lesion (*) which extends into the right masticator space and displaces the adjacent musculature and vessels. (b) Greyscale image of the lesion $(*)$ revealing fluid-fluid levels without significant flow on Doppler (not shown).

(c) These findings are consistent with a lymphatic predominant malformation component. Fluoroscopic image from contrast injection via single percutaneous access into the lesion $(*)$ reveals an isolated macrocystic LM; no venous drainage or extravasation. This lesion was sclerosed using Doxycycline. There was resolution of the swelling and patient remained asymptomatic for 12 months at which point she redeveloped swelling. (d) Ultrasound at that time reveals a persistent cavity, although much smaller than on original presentation $(\mathrm{X})$.

(e) Fluoroscopic image from contrast injection via single percutaneous access into the lesion $(\mathrm{X})$ reveals decreased size of the cavity and new communication with the external jugular vein (arrows) concerning for predominant venous component.

(f) Subsequent T2-weighted coronal MRI reveals a complicated multicystic appearance of the lesion $(O)$ in the right submandibular space with diffuse enhancement (not shown), which is confirmed to be predominantly a venous malformation on fluoroscopic injection of contrast $(\mathbf{g})$; the communication with the external jugular vein has resolved. This lesion $(O)$ was then sclerosed using STS
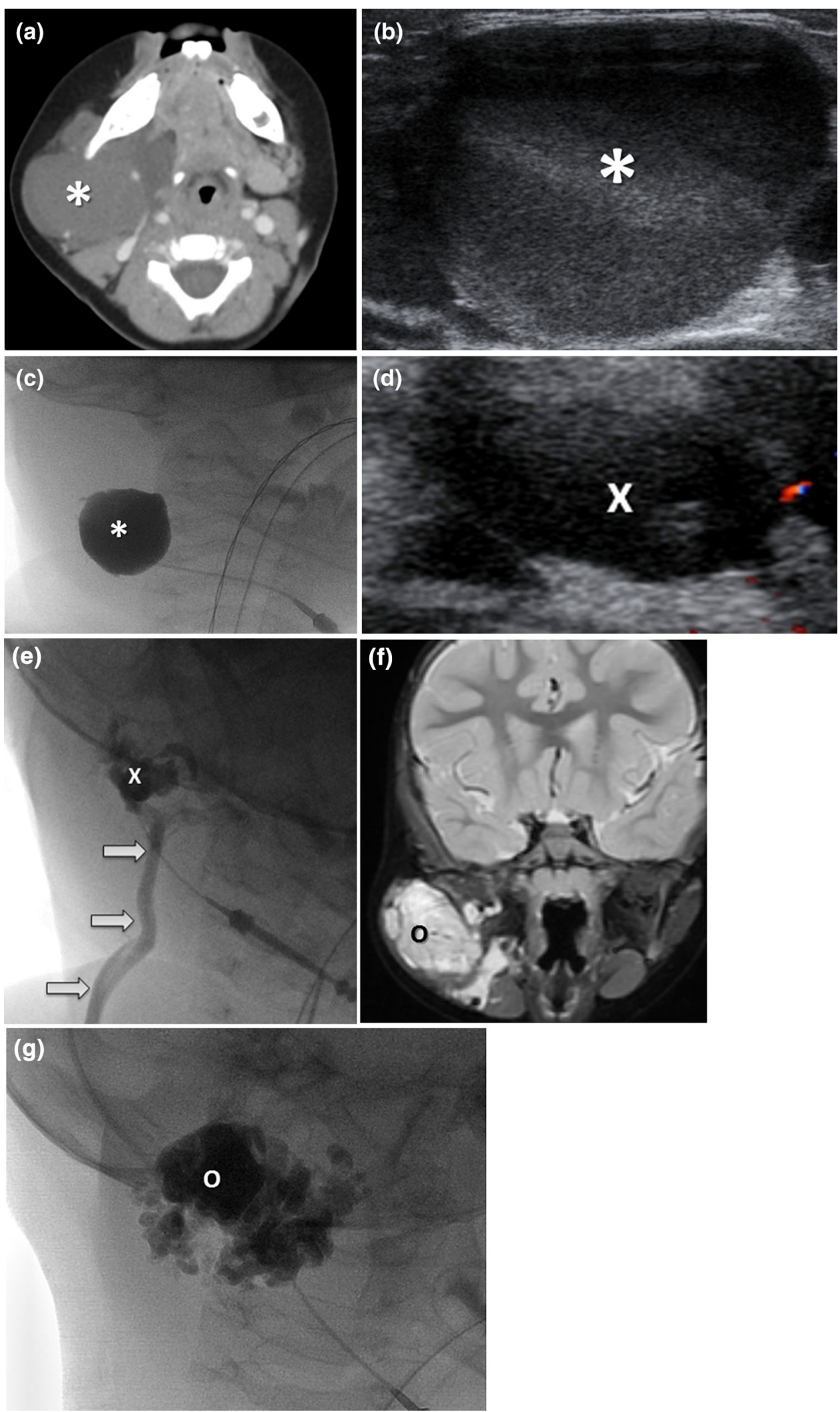

to prevent upward flow to the eye, or compressing the vein connections around the glabella of the upper nasal area can effectively prevent non-target embolization into the cavernous sinus. Another consideration is when sclerotherapy is performed in proximity to the parotid gland, particularly near the medial third of the gland, as damage to the 
Table 1 Common sclerotherapy agents for endovascular management of vascular malformations

\begin{tabular}{|c|c|c|c|c|c|c|}
\hline $\begin{array}{l}\text { Sclerotherapy } \\
\text { agent }\end{array}$ & $\begin{array}{l}\text { Primary } \\
\text { lesions } \\
\text { types } \\
\text { treated }\end{array}$ & Mechanism & Concentrations & Maximum dose & Key advantages & Key disadvantages \\
\hline Alcohol & $\begin{array}{l}\text { VM (slow } \\
\text { flow), } \\
\text { LM, } \\
\text { AVM }\end{array}$ & $\begin{array}{l}\text { Chemically injuring the } \\
\text { vascular endothelium } \\
\text { and denaturing blood } \\
\text { protein, which results } \\
\text { in an intense } \\
\text { thrombosis }\end{array}$ & $\begin{array}{l}\text { Typically } 95 \\
\text { or } 100 \% \\
\text { solution }\end{array}$ & $0.5-1 \mathrm{~mL} / \mathrm{kg}$ & $\begin{array}{l}\text { Most potent } \\
\text { sclerosant available } \\
\text { especially for large } \\
\text { VM }\end{array}$ & $\begin{array}{l}\text { Highest reported rate of } \\
\text { adverse side effects } \\
\text { of all agents (dose- } \\
\text { dependent acute } \\
\text { pulmonary } \\
\text { hypertension, } \\
\text { vasospasm, cardiac } \\
\text { arrese, CNS } \\
\text { depression) }\end{array}$ \\
\hline Sotradecol & $\begin{array}{l}\text { VM (slow } \\
\text { flow), } \\
\text { varices, } \\
\text { LM }\end{array}$ & $\begin{array}{l}\text { Acts on venous } \\
\text { endothelium to } \\
\text { induce sclerosis by } \\
\text { interference with cell } \\
\text { membrane lipids. }\end{array}$ & $1,3 \%$ & $0.5 \mathrm{mg} / \mathrm{kg}$ & $\begin{array}{l}\text { Excellent safety } \\
\text { profile, foam } \\
\text { preparation } \\
\text { improves } \\
\text { endothelial surface } \\
\text { contact }\end{array}$ & $\begin{array}{l}\text { Frequent recurrence, } \\
\text { Superficial skin } \\
\text { breakdown frequently } \\
\text { reported }\end{array}$ \\
\hline Polidocanol & $\begin{array}{l}\text { VM (slow } \\
\text { flow), } \\
\text { varices }\end{array}$ & $\begin{array}{l}\text { Acts on venous } \\
\text { endothelium to } \\
\text { induce sclerosis by } \\
\text { interference with cell } \\
\text { membrane lipids. }\end{array}$ & $0.5,1,2,3 \%$ & $2 \mathrm{mg} / \mathrm{kg}$ & $\begin{array}{l}\text { Excellent safety } \\
\text { profile, foam } \\
\text { preparation } \\
\text { improves } \\
\text { endothelial surface } \\
\text { contact, inherent } \\
\text { local anesthetic } \\
\text { properties }\end{array}$ & $\begin{array}{l}\text { Frequent recurrence, } \\
\text { inadvertent nontarget } \\
\text { embolization due to } \\
\text { high solubility } \\
\text { reported }\end{array}$ \\
\hline Doxycycline & LM & $\begin{array}{l}\text { Unclear-may induce } \\
\text { inflammatory } \\
\text { reaction within the } \\
\text { endothelial-lined } \\
\text { cavity resulting in } \\
\text { deposition of fibrin } \\
\text { and collagen and } \\
\text { eventual involution } \\
\text { of cavity }\end{array}$ & 5 to $20 \mathrm{mg} / \mathrm{mL}$ & $150 \mathrm{mg}$ to $1 \mathrm{G}$ & $\begin{array}{l}\text { High efficacy in } \\
\text { mixed lesions, } \\
\text { excellent safety } \\
\text { profile, well } \\
\text { tolerated, can be } \\
\text { effective even with } \\
\text { microcystic } \\
\text { subtypes, } \\
\text { inexpensive }\end{array}$ & $\begin{array}{l}\text { Very painful during } \\
\text { injection, reports of } \\
\text { constitutional } \\
\text { symptoms, local } \\
\text { erythema and } \\
\text { swelling. Unclear } \\
\text { long term risk of } \\
\text { tooth discoloration in } \\
\text { children }<2 y\end{array}$ \\
\hline Bleomycin & $\begin{array}{l}\text { VM (slow } \\
\text { flow), } \\
\text { LM }\end{array}$ & $\begin{array}{l}\text { Unclear-may cause } \\
\text { damage to } \\
\text { endothelial cells via } \\
\text { unknown } \\
\text { inflammatory } \\
\text { pathway }\end{array}$ & 1 to $2 \mathrm{mg} / \mathrm{mL}$ & $\begin{array}{l}\text { No more than } 1 \mathrm{mg} / \\
\mathrm{kg} \text { per session, } \\
\text { more than } \\
2 \text { weeks between } \\
\text { sessions, and no } \\
\text { greater than } 5 \text { to } \\
6 \mathrm{mg} / \mathrm{kg} \text { lifetime } \\
\text { dose }\end{array}$ & $\begin{array}{l}\text { Excellent } \\
\text { effectiveness for } \\
\text { macrocystic } \\
\text { morphology }\end{array}$ & $\begin{array}{l}\text { Rare reports of } \\
\text { pulmonary toxicity }\end{array}$ \\
\hline $\begin{array}{l}\text { OK } 432 \\
\text { (Picibanil) }\end{array}$ & LM & $\begin{array}{l}\text { Biologic product } \\
\text { created from the } \\
\text { incubation of group } \\
\text { A streptococcus with } \\
\text { penicillin- } \\
\text { immunologic } \\
\text { reaction causes } \\
\text { inflammation } \\
\text { resulting in adhesion } \\
\text { and sclerosis of cyst }\end{array}$ & $0.01 \mathrm{mg} / \mathrm{mL}$ & $\begin{array}{l}0.2 \mathrm{mg} \text { of } \mathrm{OK}-432 \\
\text { per single } \\
\text { injection }\end{array}$ & $\begin{array}{l}\text { Excellent } \\
\text { effectiveness for } \\
\text { macrocystic } \\
\text { morphology }\end{array}$ & $\begin{array}{l}\text { Microcystic LMs } \\
\text { respond poorly or not } \\
\text { at all; moderate rate } \\
\text { of side effects. Rare } \\
\text { anaphylaxis in } \\
\text { patients with allergy } \\
\text { to penicillin }\end{array}$ \\
\hline
\end{tabular}

facial nerve and subsequent facial paralysis can occur. Finally, for patients with VM in the tongue, floor of the mouth, parapharyngeal area, and soft palate, the airway may be compromised postoperatively; prolonged endotracheal intubation or prophylactic tracheotomy may be needed. In our practices all craniofacial VM sclerotherapy patients receive IV steroids prior to treatment in an effort to reduce airway compromise and inflammation around nerves. 
Fig. 2 Low-flow (venous) malformation sclerotherapy. (a) Axial T2-weighted MRI image demonstrates a heterogeneous mass (*) along the right submandibular soft tissues. (b) Fluoroscopic image taken after contrast injection of the lesion via percutaneous access demonstrates a large venous malformation $(*)$ with prominent draining vein (arrows) which was compressed during sclerotherapy which was performed with STS (not shown)
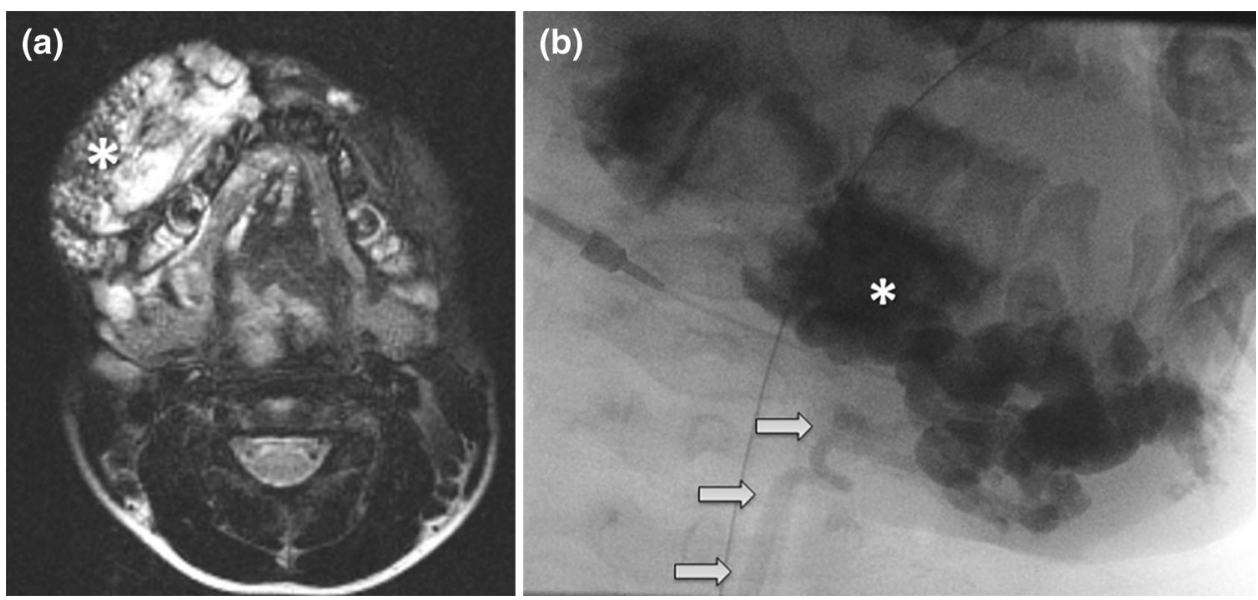

Choice of sclerosant agent is highly practice dependent. There have been no prospective randomized trials for sclerotherapy agents for VM. A lack of uniformity in endovascular treatment approach, protean manifestation of the VM lesions, and absence of a consensus clinical management protocol all are significant barriers to performing comparative effectiveness research. To date, the most common agents used appear to be ethanol and sodium tetradecyl sulfate (STS) foam. Other drugs used as sclerosing agents in the treatment of VM include ethanolamine, diatrizoate acid, quinoline, poppy oil, hypertonic glucose, tetracycline or doxycycline, Ethibloc, urea, and OK-432 [21].

Ethanol is the most effective sclerosant agent available, however, it is also the most toxic [5, 19, 22-24] ethanol works by causing instant precipitation of endothelial cell proteins and rapid thrombosis. In adults, $1 \mathrm{~mL} / \mathrm{kg}$ (or $60 \mathrm{~mL}$ ) per session should never be exceeded, and in pediatric patients, a maximum dose of $0.5 \mathrm{mg} / \mathrm{kg}$ per session is recommended; treatments with more than $1 \mathrm{~mL} / \mathrm{kg}$ lead to increased risk of respiratory depression, cardiac arrhythmias, seizures, and rhabdomyolysis [18]. Injection of less than $0.14 \mathrm{ml} / \mathrm{kg}$ body weight every $10 \mathrm{~min}$ obviates the occurrence of cardio-pulmonary collapse [18]. In a series of 60 patients with head and neck VM treated with ethanol, $68 \%$ experienced complete response with a $10 \%$ complication rate [25]. In another larger series of 158 head and neck VM patients, $16 \%$ of patients had a complete response, with a much higher $27 \%$ of these patients experiencing a complication [8]. Finally, a series of 87 patients with craniofacial VMs treated with ethanol sclerotherapy, $32 \%$ had an excellent response with a $5 \%$ complication rate [23].

STS foam is the sclerosant of choice in our practice, and a safe, effective approach for endovascular management. Mechanism of action includes damage to vascular endothelium cells, promoting thrombosis, and inflammation with subsequent fibrosis; the selectivity of action on endothelium of the foam reduces the risk of tissue damage, however, more treatment sessions are required on average to achieve response rates comparable (or better) than ethanol sclerotherapy. STS is available in 1 and $3 \%$ concentrations, and is most commonly mixed into foam for injection either by mixing with air alone or with equal parts of ethiodol. Although far less literature exists than for ethanol, sclerotherapy response rates as high as $90 \%$ have been described in extremity VM with $3 \%$ STS foam sclerotherapy after a mean of four treatment sessions [26]. The total dosage is determined by the location, size, and the patient's age, rarely exceeding more than $15 \mathrm{~mL}$ per injection. If repeat sessions are needed, then injection is repeated at an interval of 6 to 8 weeks, and not more than four consecutive sessions.

In patients with extensive VMs in whom a low fibrinogen level is present (less than $200 \mathrm{mg} / \mathrm{dL}$ ), low molecularweight heparin is recommended for 2 weeks pretreatment and posttreatment. If fibrinogen drops below 100 post procedure, patient may require cryoprecipitate. This therapy reduces the consumptive coagulopathy of the extensive $\mathrm{VM}$, a phenomenon termed localized intravascular coagulopathy (LIC) [19]. The presence of LIC can result in disseminated intravascular coagulopathy (DIC) during trauma or surgery, and is a very important consideration for combined endovascular/surgical cases [27].

After sclerotherapy, the VM will be firm to palpation, and patients can expect swelling to gradually increase, peaking roughly $24 \mathrm{~h}$ after the procedure. In our practices, if the lesion involves the airway, the patient may need to be kept intubated overnight in the intensive care unit. The affected area is kept elevated and ice packs are applied to minimize swelling. Patients receive IV fluids at twice the maintenance dose before, during, and after the sclerotherapy for $24 \mathrm{~h}$, and urine output is closely monitored for hemoglobinuria. Appropriate IV and oral analgesics and antiinflammatory agents are prescribed in the hospital and for 1-2 weeks after discharge. Unlike extremity lesions, which will benefit by the use of compression garments 
which limit swelling and discomfort, head and neck VMs cannot be treated in this fashion.

Combined endovascular and surgical approaches to craniofacial VM lesions have been shown an effective strategy for management, particularly of challenging or high risk lesions (lip, eyelid, parotid, oral cavity, etc.). Preoperative sclerotherapy of facial VMs has been performed, and found to be associated with less operative time per lesion volume and less operative blood loss [28•]. One method includes pre-embolizing the malformation using $n$ butyl cyanoacrylate (n-BCA) glue prior to same day surgical resection [29*0]. This glue is approved by the US Food and Drug Administration for high-flow cerebral arterial malformations and has been used extensively to treat intracranial and extracranial AVMs. After percutaneous access of the $\mathrm{VM}, n$-BCA is dispersed under direct fluoroscopic guidance into the venous channels in contact with the vessel wall. There are two primary goals: first, the blood in the lesion is displaced by the solidified glue reducing intraoperative bleeding, and second, the hardened glue presents a palpable demarcation line between the VM and healthy tissue for precise surgical removal. In a series of 11 patients who were treated with same day preoperative $n$-BCA glue followed by surgical resection, all patients were closed primarily and none of the patients experienced lesion persistence or post-procedural complications [29••]. Other agents, such as Ethylene-vinyl alcohol copolymer (Onyx), a liquid polymer, may also be useful for preoperative embolization of VMs before resection. More conventional combined strategies include sclerotherapy to initially control the lesion, followed by surgical resection within several days.

\section{Lymphatic Malformations}

Lymphatic malformations (LMs) are congenital lesions derived from lymphatic tissue that results from defective embryologic development of the primordial lymphatic channels. The incidence of LMs is 1.2-2.8 \%, approximately $50 \%$ is present at birth and $90 \%$ is diagnosed before 2 years of age [30]. As a vascular malformation subtype, they are considered low-flow vascular malformations; these lesions are further divided into microcystic (cysts $<1 \mathrm{~cm}$ ), macrocystic (cysts $>1 \mathrm{~cm}$ ), or mixed. While seemingly arbitrary, this distinction instead has very important implications for treatment. LMs usually present as diffuse soft tissue thickening and grow in proportion to the patient; a clinical hallmark of LM is periodic swelling that occurs, usually but not always, temporally related to a systemic illness such as a respiratory virus (Fig. 3).

Swelling may also be due to hemorrhage or lymphatic obstruction, the former more common in "mixed" lesions that contain some component of venous malformation or communication with vascular structures. Because they can swell rapidly and unpredictably, craniofacial LMs can be life-threatening lesions if the airway is threatened, and aggressive management is pursued, including tracheostomy and staged resections for large lesions (Fig. 3). LMs that involve the suprahyoid neck and involve the mucosa are commonly and frequently infected primarily. Orbital lesions can present with pain, swelling, proptosis, and other mechanical dysfunction, sometimes suddenly. Finally, an underlying cerebral developmental anomaly is seen in $45 \%$ of patients with orbital involvement [20,31-35]. In direct contrast to $\mathrm{VM}$, on physical examination the lesions cannot be compressed as readily, and do not become distended with dependant positioning or Valsalva. When doubt exists, pathologic evaluation and the positive stain for D2-40 antibody will confirm the diagnosis [36].

The endovascular approach to manage LMs is well described and often quite effective in macrocystic lesions in particular. A staging system has been proposed [37], but similar to VM management, is seldom used in practice. Multiple sclerosing agents have been used effectively for the treatment of LMs, including ethanol, sodium tetradecyl sulfate, doxycycline, Ethibloc, OK 432, and bleomycin. As in VM treatment, there is wide variation in treatment protocols used and variable results obtained between studies, such that there is no clear consensus as to when sclerotherapy is indicated, what agents offer the most benefit, and how these agents should be administered for optimal results. The most common agents include ethanol, doxycycline, and bleomycin.

The objective of LM sclerotherapy involves first accessing the lesion percutaneously, typically with imaging guidance. In our practices, a $20-22 \mathrm{G}$ angiocath-sheathed needles are used to puncture the largest cavity under ultrasound guidance; in large lesions an $18 \mathrm{G}$ sheathed needle can be used to permit the passage of $0.038^{\prime \prime}$ working guidewires or, alternatively, larger sheathed needles can be used; both will permit subsequent drainage catheter placement. The goal with the initial access is to aspirate as much fluid as possible, in multiloculated lesions often several access points are required. Once drained, contrast is injected into the lesion under fluoroscopic visualization to define the lesion size, relationship to other structures, and presence of unexpected findings such as venous communication or additional cavities. Once defined, the lesion is again emptied and the sclerosing agent, often mixed with a small quantity of contrast, is injected again under fluoroscopic visualization. The injection should be stopped immediately if abnormal change in the skin color, such as pallor or cyanosis, occurs. In our practices, we prefer to leave the sclerosant to dwell and do not aspirate; in large lesions managed with drainage catheters, the sclerosant is 

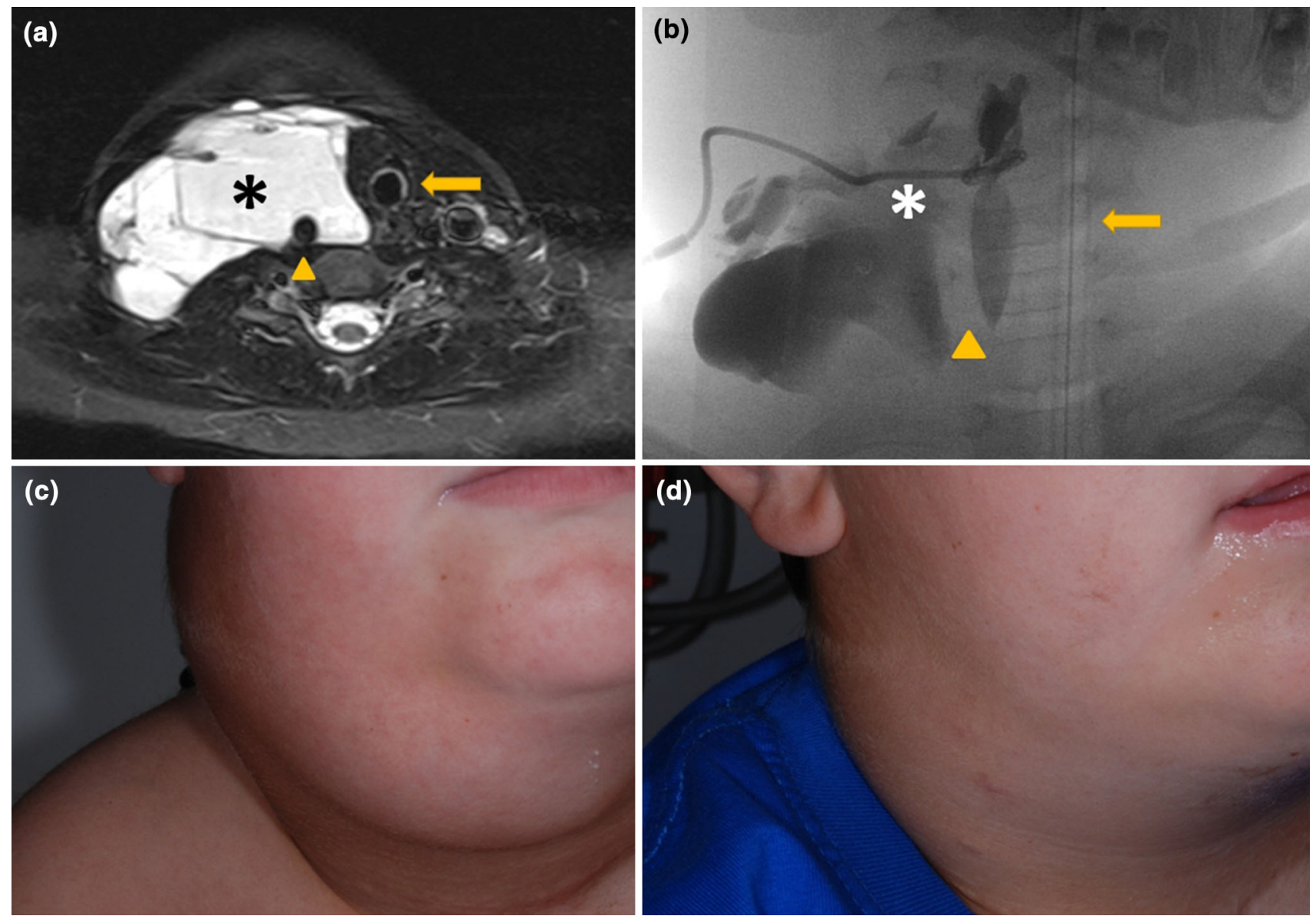

Fig. 3 Lymphatic malformation in the right cervical neck. (a) T2 fat suppressed axial MR image of the neck demonstrates a large septated fluid-signal mass in the left cervical neck (*) causing leftward shift of the trachea (arrow) and insinuating around the right common carotid artery (arrowhead). (b) Fluoroscopic image taken after percutaneous image guided pigtail drain placement into the lymphatic malformation in the right cervical neck $(*)$ followed by sclerotherapy using

left overnight prior to drainage. The drain can be left in place over several days and repeated daily irrigation with sclerosant can be performed until roughly $<10 \%$ of the original volume remains [20].

In contrast to the larger macrocystic LM, microcystic lesions are much more challenging to treat and respond less definitively to sclerotherapy agents (Fig. 4). When larger cysts are present, these are preferentially treated in hopes that communication is present with the smaller cysts to allow for sclerosant to distribute. Unlike macrocystic lesions, patients with microcystic LM will often require multiple sessions to achieve measurable result; in our practices, medical management of these lesions has enjoyed modest success with Rapamycin in select cases [38].

Of the various available agents, the most extensively studied and commonly used worldwide for LM sclerotherapy is OK432 (Picibanil), a lyophilized mixture of group A Streptococcus. Originally conceived as an immunotherapeutic agent in the

Doxycycline. Note the improved rightward deviation of the airway as evidenced by straightening of the endotracheal tube course (arrow) and impression of the right common carotid on the contrast filled lesion (arrowhead), similar to comparison MR. (c) Before and (d) after treatment photographic images of the patient's lymphatic malformation

treatment of gastric and lung carcinoma, it was used as an experimental sclerosant in the treatment of an LM in 1987 [39]. The protocol for OK- 432 is injection of $0.01 \mathrm{mg} / \mathrm{mL}$ dilution of OK-432 in physiological serum for the desired volume [39, 40]. The therapeutic response of OK- 432 is delayed, typically taking about 6 weeks or more. Several reports have described the use of OK-432 as first-line treatment for lymphangiomas. A recent literature review found an $88 \%$ complete response rate for macrocystic lesions [41]. Although not currently approved for use in the United States, a clinical trial was performed in 182 LM patients; the group reported $94 \%$ of the patients with macrocystic disease responded to treatment, while $0 \%$ of the patients with microcystic disease responded to treatment [42]. In two other series, complete response rates of 76 and $83.5 \%$ were reported [43, 44]. Most reported adverse side effects were minor and consisted of fever, lethargy, and local inflammation; however, severe complications have been reported such as respiratory compromise requiring an emergency tracheostomy 


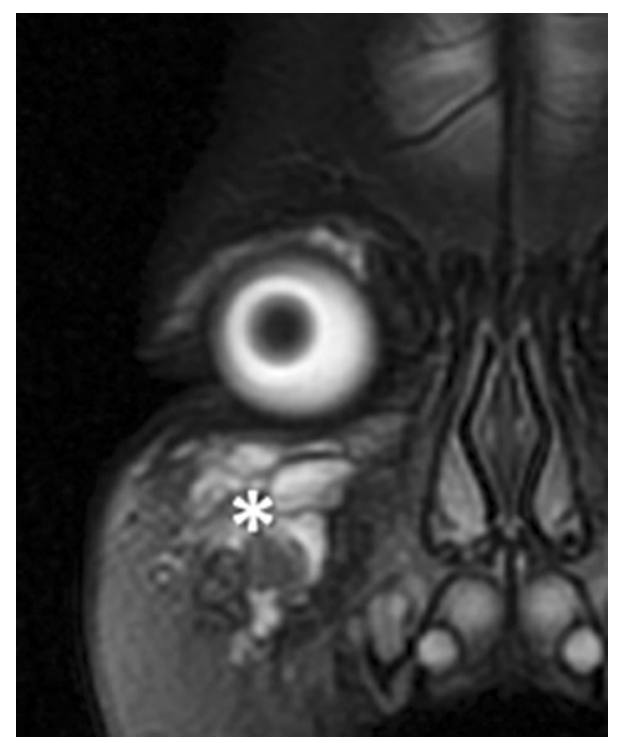

Fig. 4 Microcystic lymphatic malformation (*) arising in the soft tissues inferior to the right orbit on coronal T2 fat suppressed image (a) and greyscale ultrasound image (b). This lesion was treated using doxycycline with clinical resolution of the swelling

immediately after treatment of a large cervical lymphangioma with an intrathoracic extension, cervical cellulitis 4 weeks after therapy requiring intravenous (IV) antibiotics, and proptosis due to intracystic hemorrhage 4 weeks after therapy of a lymphangioma adjacent to the left orbit [45].

Doxycycline is also a commonly used agent, and given the more limited FDA approved agents, is preferred by many US practitioners. As a derivative of tetracycline, it was first explored as a sclerosant for pleurodesis of malignant effusions with no significant side effects. The exact mechanism by which doxycycline is as effective as a sclerosant is unknown; the typical inflammatory reaction and syndromic fever and redness that is typical after OK432 injection, does not occur. It has been speculated that Doxycycline therapy inhibits matrix metalloproteinases and suppresses the vascular endothelial growth factorinduced angiogenesis and lymphangiogenesis [46]. Although protocols vary widely, when used for sclerotherapy it is injected as a solution of $10 \mathrm{mg} / \mathrm{mL}$ (range from 5 to $20 \mathrm{mg} / \mathrm{mL}$ ), and the maximum dose can range from $150 \mathrm{mg}$ to $1 \mathrm{G}$, depending on the size of the lesion. In macrocystic LM, several series have described complete response rates with single treatment in $90 \%$ of cases [33, 47]. Also, unlike other agents, including OK-432, published reports have demonstrated efficacy in microcystic lesions, with response rates in one large series of up to $83 \%$ [48] Doxycycline causes severe pain during injection which lasts for several hours afterward, leading to the common practice of general anesthesia for most patients. Other adverse effects of Doxycycline have been described in neonates, including hemolytic anemia, hypoglycemia, and metabolic acidosis, and as a result the maximum dose per session is often limited to between 100 and $150 \mathrm{mg}$. Finally, due to the high incidence of spontaneous infection together with an increased risk on accessing the lesion, prophylactic antibiotics have been recommended immediately before LM sclerotherapy [32, 33, 49].

Bleomycin is another widely used agent for lymphatic malformation sclerotherapy, demonstrated in multiple studies to be both safe and effective. In a retrospective review of $70 \mathrm{LM}$ patients treated with intralesional injection of bleomycin, $47 \%$ achieved excellent response, with recurrence in less than $10 \%$ [50] In another series of 200 patients with LM treated with intralesional injection of bleomycin, $87 \%$ of patients demonstrated complete resolution and recurrence rate of $13 \%$ [51]. Dosing per injection is $1 \mathrm{~mL} / \mathrm{cm}^{2}$ of the lesion as determined by clinical measurement, the maximal dose for one injection is $8 \mathrm{mg}$, and the total dose should not exceed $40 \mathrm{mg}$ in an adult patient. After injection, the lesion is compressed for $5 \mathrm{~min}$ to prevent bleeding and effusion of the sclerosant. If repeated treatment is required, the appropriate interval is 3-4 weeks. If no response is noted after two injections, other treatment options should be considered rather than repeated injections. A treatment cycle often consists of 3-5 sessions. The dosage for children should be reduced accordingly.

\section{High-Flow Vascular Malformations}

AVMs are among the most rare of the vascular malformations, with an estimated prevalence of $0.0001 \%$, over half of these involve the head and neck [52]. They tend to grow at the same rate as the individual, but can show accelerated growth at puberty, during pregnancy, and in some cases after trauma or after intervention. In lesions located in areas accessible to physical examination, they may present as a soft-tissue mass, with or without palpable pulsation or thrill. They are typically nontender to palpation and will not demonstrate morphologic changes with positioning.

AVMs commonly present in varying manifestations, and as with the other vascular malformation types, often depends on the anatomic location, size, and age of the patient. Clinical and angiographic classification schemes have been proposed, the most often cited based on nidal morphology [53]. Clinical findings in AVM include ischemia, pain, growth disturbances, bleeding, and rarely, high-output cardiac failure.

Treatment of high-flow vascular malformations is difficult. With modern catheters and embolic therapies, many of which were initially developed for the management of intracranial AVM, endovascular embolization is often the treatment option most likely to succeed. The principle goal of therapy for AVMs is to obliterate the nidus, which can 
be identified angiographically as the physical site where shunting occurs [54]. From an endovascular approach, this requires delivering an embolic agent within the nidus; this can be performed using a transarterial approach, direct percutaneous puncture of the nidus, or a retrograde transvenous approach, all of which have been described [5557]. The consequences of ill-planned or improper treatment, such as misidentification or incomplete obliteration of the nidus, have been shown to stimulate the AVM lesion into a proliferative state. Many recent series call into question the long term efficacy of AVM treatment, both surgical and endovascular. In a large retrospective series looking at AVM treatment outcomes reported a high rate of recurrence after embolization or resection, with most recurrences occurring within the first year after intervention (98\% with embolization alone, $87 \%$ surgery with or without embolization); it was reported that after 5 years without recurrence, long term control was more likely [58]. Therefore, during treatment planning for AVMs it is important to recognize that in all but the most isolated lesions, complete cure is often not possible, and the complication risks can be severe. This reality, in light of the often young age at presentation, reinforces that the risks of intervention and the clinical problem at hand must be strongly considered and discussed at length with patients.

In our practices, we use general anesthesia for virtually every AVM embolization procedure; the importance of optimized imaging, physiologic monitoring, and overall comfort for what often tends to be a long case more than justify any additional risks, time, and expense. The treatment approaches for AVMs vary widely, but most often begin with careful review of contrast-enhanced cross-sectional imaging, preferably MRI/MRA. During the initial endovascular procedure, arteriograms are performed in multiple projections to confirm anatomy, establish flow rates, and identify the nidus (the point at which arterial structures first opacify the venous drainage). Transarterial embolization is performed via a coaxial $2.8 \mathrm{~F}$ microcatheter which is guided fluoroscopically immediately adjacent to the nidus where embolization is performed (Fig. 5). Staged targeting of the AVM is performed in sequential fashion, such that over several treatments the entire nidus can be obliterated.

There are a variety of embolic agents available for use, many of which are relatively new, however, ethanol has been most extensively studied; even in experienced hands, the use of transarterial ethanol embolization for AVM demonstrates high rates of complications. For example, in one of the largest series, initial successful response rates were reported near $70 \%$, however, complications occurred in slightly more than half [59] Complications are common due to the rapid shunting characteristic of these lesions, which can result in pulmonary vasospasm, cardiac arrhythmia, and electromechanical
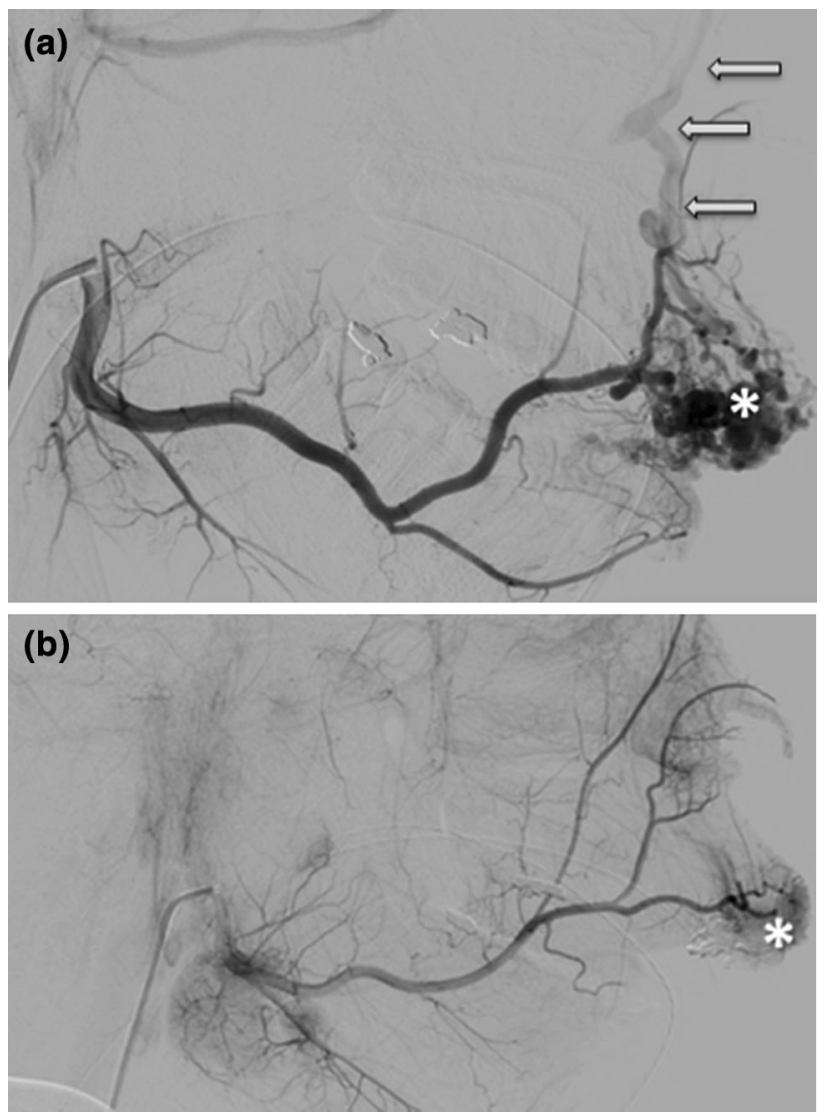

Fig. 5 High-flow AVM arising in the upper lip (*). Right external carotid arteriogram (a) demonstrates a large AVM in the superficial soft tissues of the upper lip with a tangled nidus $(*)$ and superficial draining veins leading toward the ipsilateral ophthalmic vein (arrows). (b) Repeat external carotid arteriogram after transarterial Onyx embolotherapy with nonvisualization of the nidus and draining vein

disassociation. Due to the poor safety profile, and the limitations for weight based dosing in our pediatric populations, we do not use ethanol in our practices for transcatheter embolization of AVM. Rather, we preferentially use $n$-BCA and ethylene-vinyl alcohol (Onyx, Liquid embolic system; Micro Therapeutics, Inc, Irvine, CA). While the literature on these agents is principally described for intracranial lesions, many centers have reported excellent results in peripheral and craniofacial lesions [60-63]. For most craniofacial AVMs, transcatheter Onyx embolization is an excellent agent, demonstrating permanent obliteration of the nidus via a mechanical obstruction rather than an inflammatory reaction as is the case with $n$-BCA. Although limited to a few small series, the efficacy is reported as high as $70 \%$ with very few complications, on the order of $5 \%$ or less [64-66].

Although the transarterial approach is the most widely used during embolization of high-flow AVM lesions, there are other approaches that have demonstrated excellent efficacy. One example is the use of balloon-occluded retrograde 
transvenous embolization, which is most effective in the cases of AVM that has a single draining vein. In the head and deck, a limitation of this procedure is its dependence on the venous drainage; this procedure would not be possible to treat AVMs with multiple or complex venous drainage [67].

\section{Conclusion}

Although vascular malformations are benign lesions, patients with craniofacial lesions often suffer from significant morbidity. The propensity of the lesions to infiltrate surrounding structures as well as the difficulty in distinguishing involved vital structures of head and neck from adjacent normal tissues makes successful surgical resection extremely difficult; the likelihood of postsurgical recurrence and complications is thus higher than other vascular lesions. Although various treatment options have their advantages and disadvantages, endovascular management of vascular malformations in the head and neck is safe and effective treatment modalities and should be considered an integral component of the management armamentarium based on the patient's individual status, available technology, and expertise. Wide range embolosclerotherapy agents have been described, but large studies comparing therapeutic efficacy remain to be seen. We believe that all centers treating vascular malformations should aim to provide an individualized, comprehensive multidiscipline approach in order to achieve the best treatment outcome.

\section{Compliance with Ethics Guidelines}

Conflict of Interest Matthew P. Lungren and Manish N. Patel declare that they have no conflict of interest.

Human and Animal Rights and Informed Consent This article does not contain any studies with human or animal subjects performed by any of the authors.

\section{References}

Recently published papers of particular interest have been highlighted as:

- Of importance

-• Of major importance

1. Garzon MC, Huang JT, Enjolras O, Frieden IJ. Vascular malformations: part I. J Am Acad Dermatol. 2007;56(3):353-70, quiz 371-354.

2. Mulliken JB, Glowacki J. Hemangiomas and vascular malformations in infants and children: a classification based on endothelial characteristics. Plast Reconstr Surg. 1982;69(3):412-22.

3. Brouillard P, Vikkula M. Genetic causes of vascular malformations. Hum Mol Genet. 2007;16(Spec No. 2):R140-9.
4. Lee KB, Kim DI, Oh SK, Do YS, Kim KH, Kim YW. Incidence of soft tissue injury and neuropathy after embolo/sclerotherapy for congenital vascular malformation. J Vasc Surg. 2008;48(5):1286-91.

5. Donnelly LF, Bisset GS 3rd, Adams DM. Marked acute tissue swelling following percutaneous sclerosis of low-flow vascular malformations: a predictor of both prolonged recovery and therapeutic effect. Pediatr Radiol. 2000;30(6):415-9.

6. Donnelly LF, Adams DM, Bisset GS 3rd. Vascular malformations and hemangiomas: a practical approach in a multidisciplinary clinic. AJR Am J Roentgenol. 2000;174(3):597-608.

7. Perkins JA, Manning SC, Tempero RM, et al. Lymphatic malformations: review of current treatment. Otolaryngol Head Neck Surg. 2010;142(6):795-803, 803 e791.

8. Yun WS, Kim YW, Lee KB, et al. Predictors of response to percutaneous ethanol sclerotherapy (PES) in patients with venous malformations: analysis of patient self-assessment and imaging. J Vasc Surg. 2009;50(3):581-9, 589 e581.

9. Cahill AM, Nijs EL. Pediatric vascular malformations: pathophysiology, diagnosis, and the role of interventional radiology. Cardiovasc Intervent Radiol. 2011;34(4):691-704.

10. Lacey B, Rootman J, Marotta TR. Distensible venous malformations of the orbit: clinical and hemodynamic features and a new technique of management. Ophthalmology. 1999;106(6): 1197-209.

11. - Waner M, O TM. The role of surgery in the management of congenital vascular anomalies. Tech Vasc Interv Radiol. 2013;16(1):45-50. Great discussion and review of the surgical management for many types of vascular anomalies.

12. Weinstein JM, Chamlin SL. Quality of life in vascular anomalies. Lymphat Res Biol. 2005;3(4):256-9.

13. Uehara S, Osuga K, Yoneda A, Oue T, Yamanaka H, Fukuzawa M. Intralesional sclerotherapy for subcutaneous venous malformations in children. Pediatr Surg Int. 2009;25(8):709-13.

14. Blaise S, Charavin-Cocuzza M, Riom H, et al. Treatment of lowflow vascular malformations by ultrasound-guided sclerotherapy with polidocanol foam: 24 cases and literature review. Eur J Vasc Endovasc Surg. 2011;41(3):412-7.

15. Zhao JH, Zhang WF, Zhao YF. Sclerotherapy of oral and facial venous malformations with use of pingyangmycin and/or sodium morrhuate. Int J Oral Maxillofac Surg. 2004;33(5):463-6.

16. Cabrera J, Cabrera J Jr, Garcia-Olmedo MA, Redondo P. Treatment of venous malformations with sclerosant in microfoam form. Arch Dermatol. 2003;139(11):1409-16.

17. Jin $\mathrm{Y}$, Lin X, Li W, Hu X, Ma G, Wang W. Sclerotherapy after embolization of draining vein: a safe treatment method for venous malformations. J Vasc Surg. 2008;47(6):1292-9.

18. Mason KP, Michna E, Zurakowski D, Koka BV, Burrows PE. Serum ethanol levels in children and adults after ethanol embolization or sclerotherapy for vascular anomalies. Radiology. 2000;217(1):127-32.

19. Burrows PE, Mason KP. Percutaneous treatment of low flow vascular malformations. J Vasc Interv Radiol. 2004;15(5): 431-45.

20. Alomari AI, Karian VE, Lord DJ, Padua HM, Burrows PE. Percutaneous sclerotherapy for lymphatic malformations: a retrospective analysis of patient-evaluated improvement. J Vasc Interv Radiol. 2006;17(10):1639-48.

21. Yang Y, Sun M, Hou R, et al. Preliminary study of fibrin glue combined with pingyangmycin for the treatment of venous malformations in the oral and maxillofacial region. J Oral Maxillofac Surg. 2008;66(11):2219-25.

22. Fayad LM, Hazirolan T, Carrino JA, Bluemke DA, Mitchell S. Venous malformations: MR imaging features that predict skin burns after percutaneous alcohol embolization procedures. Skeletal Radiol. 2008;37(10):895-901. 
23. Lee IH, Kim KH, Jeon P, et al. Ethanol sclerotherapy for the management of craniofacial venous malformations: the interim results. Korean J Radiol. 2009;10(3):269-76.

24. Shin BS, Do YS, Cho HS, et al. Cardiovascular effects and predictability of cardiovascular collapse after repeated intravenous bolus injections of absolute ethanol in anesthetized pigs. J Vasc Interv Radiol. 2010;21(12):1867-72.

25. Su L, Fan X, Zheng L, Zheng J. Absolute ethanol sclerotherapy for venous malformations in the face and neck. J Oral Maxillofac Surg. 2010;68(7):1622-7.

26. Khandpur S, Sharma VK. Utility of intralesional sclerotherapy with 3\% sodium tetradecyl sulphate in cutaneous vascular malformations. Dermatol Surg. 2010;36(3):340-6.

27. Dompmartin A, Acher A, Thibon P, et al. Association of localized intravascular coagulopathy with venous malformations. Arch Dermatol. 2008;144(7):873-7.

28. - James CA, Braswell LE, Wright LB, et al. Preoperative sclerotherapy of facial venous malformations: impact on surgical parameters and long-term follow-up. J Vasc Interv Radiol. 2011;22(7):953-60. Well organized series focusing on the comparitive outcomes of preoperative endovascular therapy for venous malformations.

29. • Tieu DD, Ghodke BV, Vo NJ, Perkins JA. Single-stage excision of localized head and neck venous malformations using preoperative glue embolization. Otolaryngol Head Neck Surg. 2013; 148(4):678-84. Excellent discussion regarding the protocol for an effective immediate preoperative glue embolization prior to surgical resection for craniofacial vascular malformation treatment.

30. Dickerhoff R, Bode VU. Cyclophosphamide in non-resectable cystic hygroma. Lancet. 1990;335:1474-75.

31. Mathur NN, Rana I, Bothra R, Dhawan R, Kathuria G, Pradhan T. Bleomycin sclerotherapy in congenital lymphatic and vascular malformations of head and neck. Int J Pediatr Otorhinolaryngol. 2005;69(1):75-80.

32. Shiels WE 2nd, Kenney BD, Caniano DA, Besner GE. Definitive percutaneous treatment of lymphatic malformations of the trunk and extremities. J Pediatr Surg. 2008;43(1):136-9, discussion 140.

33. Shiels WE 2nd, Kang DR, Murakami JW, Hogan MJ, Wiet GJ. Percutaneous treatment of lymphatic malformations. Otolaryngol Head Neck Surg. 2009;141(2):219-24.

34. Okazaki T, Iwatani S, Yanai T, et al. Treatment of lymphangioma in children: our experience of 128 cases. J Pediatr Surg. 2007;42(2):386-9.

35. Dubois J, Garel L, Abela A, Laberge L, Yazbeck S. Lymphangiomas in children: percutaneous sclerotherapy with an alcoholic solution of zein. Radiology. 1997;204(3):651-4.

36. Al-Adnani M, Williams S, Rampling D, Ashworth M, Malone M, Sebire NJ. Histopathological reporting of paediatric cutaneous vascular anomalies in relation to proposed multidisciplinary classification system. J Clin Pathol. 2006;59(12):1278-82.

37. de Serres LM, Sie KC, Richardson MA. Lymphatic malformations of the head and neck. A proposal for staging. Arch Otolaryngol Head Neck Surg. 1995;121(5):577-82.

38. Hammill AM, Wentzel M, Gupta A, et al. Sirolimus for the treatment of complicated vascular anomalies in children. Pediatr Blood Cancer. 2011;57(6):1018-24.

39. Ogita S, Tsuto T, Tokiwa K, Takahashi T. Intracystic injection of OK-432: a new sclerosing therapy for cystic hygroma in children. Br J Surg. 1987;74(8):690-1.

40. Ogita S, Tsuto T, Tokiwa K, Takahashi T. Treatment of cystic hygroma in children with special reference to OK-432 therapy. Z Kinderchir. 1987;42(5):279-81.

41. Poldervaart MT, Breugem CC, Speleman L, Pasmans S. Treatment of lymphatic malformations with OK-432 (Picibanil): review of the literature. J Craniofac Surg. 2009;20(4):1159-62.
42. Smith MC, Zimmerman MB, Burke DK, Bauman NM, Sato Y, Smith RJ. Efficacy and safety of OK-432 immunotherapy of lymphatic malformations. Laryngoscope. 2009;119(1):107-15.

43. Ohta N, Fukase S, Watanabe T, Ito T, Aoyagi M. Effects and mechanism of OK-432 therapy in various neck cystic lesions. Acta Otolaryngol. 2010;130(11):1287-92.

44. Yoo JC, Ahn Y, Lim YS, et al. OK-432 sclerotherapy in head and neck lymphangiomas: long-term follow-up result. Otolaryngol Head Neck Surg. 2009;140(1):120-3.

45. Giguere CM, Bauman NM, Sato Y, et al. Treatment of lymphangiomas with OK-432 (Picibanil) sclerotherapy: a prospective multi-institutional trial. Otolaryngol Head Neck Surg. 2002;128(10):1137-44.

46. Hurewitz AN, Wu CL, Mancuso P, Zucker S. Tetracycline and doxycycline inhibit pleural fluid metalloproteinases. A possible mechanism for chemical pleurodesis. Chest. 1993;103(4):1113-7.

47. Nehra D, Jacobson L, Barnes P, Mallory B, Albanese CT, Sylvester KG. Doxycycline sclerotherapy as primary treatment of head and neck lymphatic malformations in children. J Pediatr Surg. 2008;43(3):451-60.

48. Burrows PE, Mitri RK, Alomari A, et al. Percutaneous sclerotherapy of lymphatic malformations with doxycycline. Lymphat Res Biol. 2008;6(3-4):209-16.

49. Legiehn GM, Heran MK. Classification, diagnosis, and interventional radiologic management of vascular malformations. Orthop Clin North Am. 2006;37(3):435-74, vii-viii.

50. Niramis R, Watanatittan S, Rattanasuwan T. Treatment of cystic hygroma by intralesional bleomycin injection: experience in 70 patients. Eur J Pediatr Surg. 2010;20(3):178-82.

51. Zhong PQ, Zhi FX, Li R, Xue JL, Shu GY. Long-term results of intratumorous bleomycin-A5 injection for head and neck lymphangioma. Oral Surg Oral Med Oral Pathol Oral Radiol Endod. 1998;86(2):139-44.

52. Jacobs AH, Walton RG. The incidence of birthmarks in the neonate. Pediatrics. 1976;58(2):218-22.

53. Cho SK, Do YS, Shin SW, et al. Arteriovenous malformations of the body and extremities: analysis of therapeutic outcomes and approaches according to a modified angiographic classification. J Endovasc Ther. 2006;13(4):527-38.

54. Lee BB, Do YS, Yakes W, Kim DI, Mattassi R, Hyon WS. Management of arteriovenous malformations: a multidisciplinary approach. J Vasc Surg. 2004;39(3):590-600.

55. Mallios A, Laurian C, Houbballah R, Gigou F, Marteau V. Curative treatment of pelvic arteriovenous malformation-an alternative strategy: transvenous intra-operative embolisation. Eur J Vasc Endovasc Surg. 2011;41(4):548-53.

56. Sasaki M, Tadokoro S, Kimura S, Mori M, Kosuda S, Tachibana M. Two cases of renal arteriovenous fistula treated by transcatheter embolization with absolute ethanol. Hinyokika Kiyo Acta urol Jpn. 1984;30(3):295-8.

57. Yakes WF, Haas DK, Parker SH, et al. Symptomatic vascular malformations: ethanol embolotherapy. Radiology. 1989;170(3 Pt 2):1059-66.

58. Liu AS, Mulliken JB, Zurakowski D, Fishman SJ, Greene AK. Extracranial arteriovenous malformations: natural progression and recurrence after treatment. Plast Reconstr Surg. 2010;125(4): 1185-94.

59. Shin BS, Do YS, Lee BB, et al. Multistage ethanol sclerotherapy of soft-tissue arteriovenous malformations: effect on pulmonary arterial pressure. Radiology. 2005;235(3):1072-7.

60. Pollak JS, White RI Jr. The use of cyanoacrylate adhesives in peripheral embolization. J Vasc Interv Radiol. 2001;12(8): 907-13.

61. Kacker A, Heier L, Jones J. Large intraosseous arteriovenous malformation of the maxilla - a case report with review of literature. Int J Pediatr Otorhinolaryngol. 2000;52(1):89-92. 
62. Corsten L, Bashir Q, Thornton J, Aletich V. Treatment of a giant mandibular arteriovenous malformation with percutaneous embolization using histoacrylic glue: a case report. J Oral Maxillofac Surg. 2001;59(7):828-32.

63. Toker ME, Eren E, Akbayrak H, et al. Combined approach to a peripheral congenital arteriovenous malformation: surgery and embolization. Heart Vessels. 2006;21(2):127-30.

64. Panagiotopoulos V, Gizewski E, Asgari S, Regel J, Forsting M, Wanke I. Embolization of intracranial arteriovenous malformations with ethylene-vinyl alcohol copolymer (Onyx). AJNR Am J Neuroradiol. 2009;30(1):99-106.
65. Rennert J, Herold T, Schreyer AG, et al. Evaluation of a liquid embolization agent (Onyx) for transcatheter embolization for renal vascular lesions. Rofo. 2009;181(10):996-1001.

66. Muller-Wille R, Herold T, Jung EM, et al. Onyx (ethylene-vinylalcohol-copolymer)-a novel approach to the endovascular treatment of acute bleeding. Rofo. 2009;181(8):767-73.

67. Patel A, Fischman AM, Saad WE. Balloon-occluded retrograde transvenous obliteration of gastric varices. AJR Am J Roentgenol. 2012;199(4):721-9. 